\title{
THE RATIONALITY OF DRUG PRESCRIPTIONS AT THE GYNAECOLOGY DEPARTMENT IN A TERTIARY CARE TEACHING HOSPITAL IN KELANTAN
}

\author{
SAMI MUSTAFA ALSHAKHSHIR ${ }^{1,2^{*}}$, SYED AZHAR SYED SULAIMAN ${ }^{2,3}$, \\ MAHMOUD SADI ALHADDAD ${ }^{4}$ AND MOHD PAZUDIN 5 \\ ${ }^{1}$ College of Pharmacy, Aqaba University of Technology, Aqaba, Jordan \\ ${ }^{2}$ School of Pharmaceutical Sciences, Universiti Sains Malaysia, Pulau Pinang, Malaysia \\ ${ }^{3}$ Advanced Medical and Dental Institute, Universiti Sains Malaysia, Bertam, \\ Pulau Pinang, Malaysia \\ ${ }^{4}$ Palestine Polytechnic University, College of Medicine, Hebron, Palestine \\ ${ }^{5}$ Hospital Universiti Sains Malaysia, School of Medical Sciences, Kelantan, Malaysia
}

Published online: 24 May 2021

To cite this article: SAMI MUSTAFA ALSHAKHSHIR, SYED AZHAR SYED SULAIMAN, MAHMOUD SADI ALHADDAD \& MOHD PAZUDIN (2021) The rationality of drug prescriptions at the Gynaecology Department in a tertiary care teaching hospital in Kelantan, Malaysian Journal of Pharmaceutical Sciences, 19(1): 29-44, https://doi.org/ 10.21315/mjps2021.19.1.3

To link to this article: https://doi.org/10.21315/mjps2021.19.1.3

\begin{abstract}
The aim of this study is to assess the rational prescribing pattern of drugs for pregnant women using World Health Organization (WHO)/International Network for Rational Use of Drugs (INRUD) core drug prescribing indicators. A one-year retrospective research design from (October 2016-September 2017) was used to review pregnant women prescriptions from their medical records at Hospital Universiti Sains Malaysia (HUSM). A structured data collection form using WHO/INRUD document on prescribing indicators was used. Data was sorted and categorised according to the US Food and Drug Administration (USFDA) pregnancy classification systems and Anatomical Therapeutic Classification (ATC). Then, data was compared with the references values of WHO/INRUD. Descriptive analysis were performed using SPSS version 20. A total of 741 medical files met the study inclusion criteria. The average number of prescribed drugs per prescription and the percentage of prescribed drugs from hospital formulary list and health ministry list were within the acceptable range listed by WHO. Whereas, the percentage of pregnant women with antibiotics and injection drugs were lower than normal values $17.67 \%$ and $8.23 \%$, respectively. Percentage of prescribed drugs from categories $C$ and $D$ were $13.8 \%$ and $2.8 \%$, respectively. Whereas $24.8 \%$ of prescribed drugs were from unclassified risk category. On the other hand, multivitamins preparations were the highest category of prescriptions $17.7 \%$. Injections and number of antibiotics per encounter were lower than the recommended range listed
\end{abstract}

"Corresponding author: drsamipharma@gmail.com

(C) Penerbit Universiti Sains Malaysia, 2021. This work is licensed under the terms of the Creative Commons Attribution (CC BY) (http://creativecommons.org/licenses/by/4.0/). 
by WHO. However, a great caution and careful prescribing behaviour of physicians were noticed at gynaecology/obstetric departments and most of the prescribed medications were rational and safe during pregnancy.

Keywords: Pregnant, WHO indicators, Malaysia, Prescribing pattern, Rationality

\section{INTRODUCTION}

Using medications during pregnancy is considered as a big challenge. This is mainly due to the physiological and pharmacokinetic profile changes that occur to pregnant women which may enhance the harmful effects of drugs on both mother and unborn baby. Particularly, if the information about the safety/risk of medications used during pregnancy is insufficient (Marote 2014).

In 1985, World Health Organization (WHO) defined rationale use of drugs as "The rational use of drugs requires that patients receive medication appropriate to their clinical needs, in doses that meet their requirement for an adequate period and at the lowest cost to them and their community" (Bhartiy et al. 2008; WHO 2012). WHO reported that nearly half of all medications are irrationaly dispensed, prescribed or sold (WHO 2011).

As a general rule, all the medications are preferred to be prescribed with small doses for short periods, to avoid polypharmacy and to minimise the side effects and drugdrug interactions (Salwe, Kalyansundaram and Bahurupi 2016).

The International Network for Rational Use of Drugs (INRUD) and WHO developed a tool with specific parameters that measure the rationality of drug prescriptions. This tool is highly accepted in developing countries and is used as an objective method to evaluate drug prescription pattern (WHO 2011; Hogerzeil et al. 1993).

WHO/INRUD core drug prescribing indicators are considered as a standard tool because of its feasibility, reliability, content validity and face validity which were previously approved and tested in more than thirty countries (WHO 1993).

WHO/INRUD core drug prescribing indicators can assist healthcare providers in achieving a higher level of rational prescribing of drugs through measuring specific criteria and parameters in prescriptions such as average number of prescribed drugs per prescription, percentage of drugs which are written by generic name, rate of antibiotics and injections prescribed per patient and adherence level to formulary/essential drug list (EDL). The WHO/INRUD have normal reference value for each indicator and if the results of these indicators were more or less than the normal reference values, they were considered irrational. While if the results of these indicators were within the normal reference values, they were considered rational (WHO 1993).

Unfortunately, few studies are noticed regarding the types of prescribed drugs and prescribing pattern of drugs during pregnancy in different nations. Also, the majority of studies did not clarify the primary indications for prescriptions and if the medications were used for chronic disease or pregnancy-related diseases (Andrade et al. 2004; Haramburu, Miremont and Moore 2000).

In Malaysia, limited research was found investigating the rational prescribing pattern of drugs by using WHO/INRUD core drug prescribing indicators (Kamaruzaman and Ibrahim 2006). Thus, the aim of this study is to assess the rational prescribing pattern of drugs for pregnant women using WHO/INRUD drug prescribing indicators.

Malay J Pharm Sci, Vol. 19, No. 1 (2021): 29-44 


\section{METHODS}

A one-year (October 2016-September 2017) retrospective research design was used during the study at the Obstetrics/Gynaecology Department of Hospital Universiti Sains Malaysia (HUSM). All pregnant women who visited the antenatal clinic at HUSM during study period were included. However, pregnant women who were not prescribed with medications, or only were prescribed medications for laboring during their most recent visit to the antenatal clinic were excluded.

According to $\mathrm{WHO}$ document, it was stated that the minimum required sample size to use WHO/INRUD tool is 600 participants for each institution. While it is advised to increase the sample size whenever possible (WHO 1993). According to the statistics from gynaecology department, there are around 2,600 patients who visit the gynaecology department with a total of 8,000 visits per year. This is due to the repeated visits of pregnant women to the gynaecology department within the same year during their pregnancy period. In addition, after consulting gynaecologists in the hospital, we were told that less than $50 \%$ of patients who visited gynaecology department are prescribed with medications and some of them are prescribed with labouring medications. Therefore, to exclude any repetitions in our study, we decided to screen a total of 2,600 medical file through using systematic random sampling technique by determining the sampling interval as: $8,000 / 2,600=3$.

A structured data collection form was developed according to WHO document (WHO 1993) and according to published peer-reviewed articles (Bataineh et al. 2013; Mary, Chandrakala and Tekulapally 2015; Mesfin et al. 2015). The research tool consists of five sections: (i) patients' demographic data; (ii) gravidity; (iii) obstetric medical history; (iv) WHO/INRUD core drug prescribing indicators and (v) US Food and Drug Administration (USFDA) pregnancy category for medicines used during pregnancy.

As well, data was calculated and compared with the standard values of $\mathrm{WHO} /$ INRUD core drug prescribing indicators as the following (WHO 1993):

Indicator 1: It indicates the percentage of prescribed drugs by generic name to measure the trend of generic name prescriptions which was calculated as (total number of prescribed drugs by generic name/total number of prescribed drugs) $\times 100$.

Indicator 2: It indicates the percentage of prescriptions with antibiotics which was calculated as (total number of encounters who prescribed with antibiotic drugs/ total number of encounters surveyed) $\times 100$.

Indicator 3: It indicates the percentage of prescriptions with an injection which was calculated as (total number of encounters who prescribed injection drugs/total number of encounters surveyed) $\times 100$.

Indicator 4: It indicates the average number of prescribed drugs per prescription to measure the degree of polypharmacy and was calculated as (total number of prescribed drugs/number of encounters surveyed).

Indicator 5: It indicates the percentage of prescribed drugs from the EDL or hospital formulary which was calculated as (total number of prescribed drugs from the essential or formulary drug list/total number of prescribed drugs) $\times 100$. 
Data was collected from the prescription that was prescribed during the most recent prescription only to avoid any duplications of prescribed drugs for the same patient since any duplication would lead to misleading results.

Data was sorted and categorised according to the USFDA pregnancy classification systems (MIMS Pte 2017; Truven Health Analytics 2012) and Anatomical Therapeutic Classification (ATC) (WHO 2018).

Descriptive analysis such as frequencies and percentiles were used to describe type and number of medications in each prescription. Data were analysed using SPSS version 22 and all tests were conducted at an alpha value of 0.05 .

\section{RESULTS}

Researchers reviewed a total of 2,600 medical files for pregnant women who attended the Gynaecology Department at HUSM within the study period. Only medical records of 741 pregnant women with a total of 1,296 prescribed drugs were selected according to the study inclusion criteria.

Table 1 represents the general characteristics of pregnant women, as nearly all medical files were related to Malay pregnant women and more than half of them were between 31 and 40 years old. Majority of pregnant women presented were multigravida $(91.6 \%)$, and $52.4 \%$ of them visited the antenatal clinic as the first time in the second trimester, whereas the majority of pregnant women $(88.0 \%)$ repeated the visits more than four times during pregnancy.

Table 1: General characteristics of pregnant women included in the study.

\begin{tabular}{llrr}
\hline Demographic variables & & Frequencies $(\boldsymbol{n})$ & Percentages (\%) \\
\hline Nationality & Malaysian & 736 & 99.3 \\
& Non-Malaysian & 5 & 0.7 \\
Race & Malay & 736 & 99.3 \\
& Chinese & 0 & 0.0 \\
& Indian & 0 & 0.0 \\
& Other & 5 & 0.7 \\
Age in years & $18-20$ & 4 & 0.5 \\
& $21-25$ & 75 & 10.2 \\
& $26-30$ & 166 & 22.4 \\
& $31-40$ & 471 & 63.6 \\
Total numbers of ANC visits & $\geq 41$ & 25 & 3.4 \\
& 1 & 8 & 1.1 \\
& 2 & 39 & 5.3 \\
& 3 & 42 & 5.7 \\
& $\geq 4$ & 652 & 88.0 \\
\hline
\end{tabular}


Table 1: (continued)

\begin{tabular}{llcc}
\hline Demographic variables & & Frequencies $(\boldsymbol{n})$ & Percentages $(\%)$ \\
\hline Time of first ANC visit & 1st trimester & 102 & 13.8 \\
& 2nd trimester & 388 & 52.4 \\
& 3rd trimester & 251 & 33.9 \\
Gravidity & Primigravida & 62 & 8.4 \\
& Multigravida & 679 & 91.6 \\
\hline
\end{tabular}

Note: $\mathrm{ANC}=$ antenatal clinic.

Table 2 shows the rationality of drug prescriptions for pregnant women according to WHO/INRUD core drug prescribing indicators during the study period. Most indicators were within the normal range of WHO reference values except for the percentage of encounters with an antibiotics and injections which were less than normal range $17.67 \%$ and $8.23 \%$, respectively.

Table 2: Prescribing pattern among pregnant woman based on the WHO/INRUD prescribing indicators.

\begin{tabular}{|c|c|c|c|c|c|}
\hline \multirow[b]{2}{*}{$\begin{array}{l}\text { (WHO/INRUD) } \\
\text { Indicators }\end{array}$} & \multicolumn{4}{|c|}{ Obtained value } & \multirow[b]{2}{*}{$\begin{array}{c}\text { Reference } \\
\text { values* } \\
\text { (WHO/INRUD) }\end{array}$} \\
\hline & $\begin{array}{c}1 \mathrm{st} \\
\text { trimester } \\
n\end{array}$ & $\begin{array}{c}\text { 2nd } \\
\text { trimester } \\
n\end{array}$ & $\begin{array}{c}\text { 3rd } \\
\text { trimester } \\
n\end{array}$ & $\begin{array}{c}\text { Total value } \\
n\end{array}$ & \\
\hline $\begin{array}{l}\text { Prescribed drugs by } \\
\text { generic name }(\%)\end{array}$ & $\begin{array}{c}145 \\
(100 \%)\end{array}$ & $\begin{array}{c}566 \\
(100 \%)\end{array}$ & $\begin{array}{c}585 \\
(100 \%)\end{array}$ & $\begin{array}{c}1,296 \\
(100 \%)\end{array}$ & $100 \%$ \\
\hline $\begin{array}{l}\text { Pregnant women with } \\
\text { antibiotic prescribed (\%) }\end{array}$ & $\begin{array}{c}6 \\
(6.66 \%)\end{array}$ & $\begin{array}{c}51 \\
(15.64 \%)\end{array}$ & $\begin{array}{c}74 \\
(22.77 \%)\end{array}$ & $\begin{array}{c}131 \\
(17.67 \%)\end{array}$ & $20 \%-26.8 \%$ \\
\hline $\begin{array}{l}\text { Pregnant women with an } \\
\text { injection prescribed (\%) }\end{array}$ & $\begin{array}{c}5 \\
(5.55 \%)\end{array}$ & $\begin{array}{c}33 \\
(10.12 \%)\end{array}$ & $\begin{array}{c}23 \\
(7.07 \%)\end{array}$ & $\begin{array}{c}61 \\
(8.23 \%)\end{array}$ & $13.4 \%-24.1 \%$ \\
\hline $\begin{array}{l}\text { Average number of } \\
\text { prescribed drug }\end{array}$ & $\begin{array}{c}145 \\
(1.61)\end{array}$ & $\begin{array}{c}566 \\
(1.73)\end{array}$ & $\begin{array}{c}585 \\
(1.80)\end{array}$ & $\begin{array}{r}1,296 \\
(1.75)\end{array}$ & $1.6-1.8$ \\
\hline $\begin{array}{l}\text { Drugs from hospital } \\
\text { formulary list }\end{array}$ & $(100 \%)$ & $(100 \%)$ & $(100 \%)$ & $(100 \%)$ & $(100 \%)$ \\
\hline $\begin{array}{l}\text { Drugs from health } \\
\text { ministry essential list }\end{array}$ & $(100 \%)$ & $(100 \%)$ & $(100 \%)$ & $(100 \%)$ & $(100 \%)$ \\
\hline
\end{tabular}

Notes: *The WHO/INRUD have normal reference values for each indicator and if the results of these indicators were more or less than the normal reference values, the results were considered irrational.

Figure 1 portrays interesting results as out of 1,296 prescribed drugs, substantial proportions $(24.5 \%$ and $34.0 \%$ ) belonged to the USFDA pregnancy categories $A$ and $B$, respectively. On the other hand, only $0.08 \%$ of drugs were prescribed from category $X$ (the contraindicated drugs during pregnancy). However, $24.80 \%$ of the prescribed drugs had no USFDA pregnancy classification. 


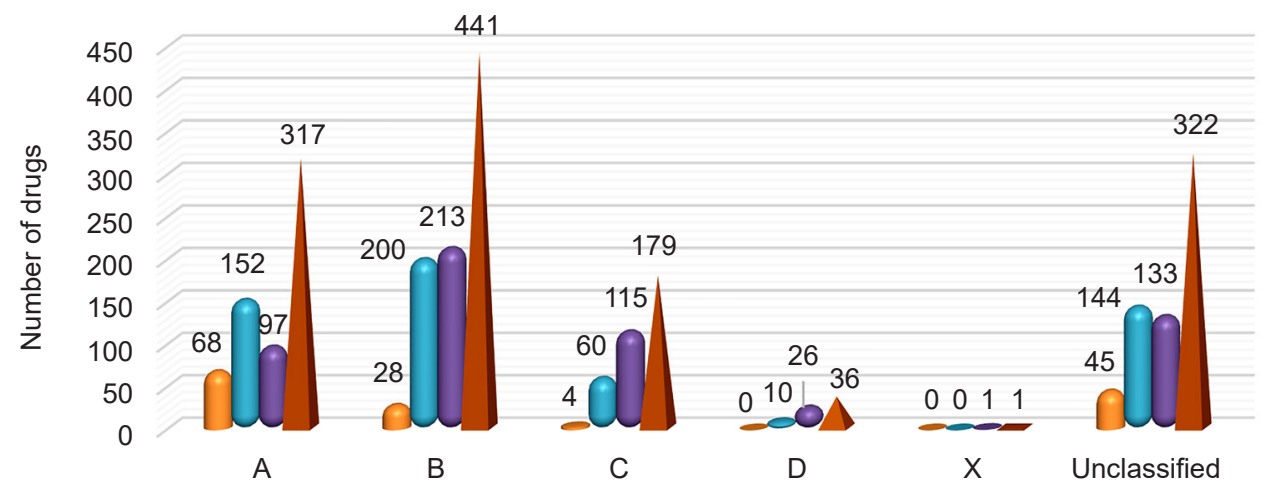

FDA classification

$\square$ First $\quad$ Second Third $\square$ Total

Notes: First trimester of pregnancy; Second trimester of pregnancy; Third trimester of pregnancy; Total of prescribed drugs in each trimester.

Figure 1: Prescriptions analysis by USFDA pregnancy categorisation system.

Table 3 shows the distribution of polypharmacy per prescription as more than half of pregnant women (55.2\%) had only one drug per prescription followed by $25.2 \%$ of pregnant women with two drugs per prescription and only small percentage of pregnant women $(1.3 \%)$ who had five drugs per prescription.

Table 3: Number of prescribed drugs per prescription.

\begin{tabular}{ccccc}
\hline No. of drugs & $\begin{array}{c}\text { 1st trimester } \\
\boldsymbol{n}(\%)\end{array}$ & $\begin{array}{c}\text { 2nd trimester } \\
\boldsymbol{n}(\%)\end{array}$ & $\begin{array}{c}\text { 3rd trimester } \\
\boldsymbol{n}(\%)\end{array}$ & $\begin{array}{c}\text { Total value } \\
\boldsymbol{n}(\%)\end{array}$ \\
\hline 1 & $53(58.9)$ & $182(55.8)$ & $174(53.5)$ & $409(55.2)$ \\
2 & $25(27.8)$ & $82(25.2)$ & $80(24.6)$ & $187(25.2)$ \\
3 & $8(8.9)$ & $32(9.8)$ & $37(11.4)$ & $77(10.4)$ \\
4 & $2(2.2)$ & $26(8.0)$ & $30(9.2)$ & $58(7.8)$ \\
5 & $2(2.2)$ & $4(1.2)$ & $4(1.2)$ & $10(1.3)$ \\
\hline
\end{tabular}

According to Table 4, the most frequently prescribed classes of drugs in accordance with ATC system were antianaemic and vitamins preparations (33.3\%), followed by respiratory drugs $(9.9 \%)$, cardiovascular drugs $(9.30 \%)$, antibacterial for systemic use $(8.0 \%)$ and diabetics therapy $(6.60 \%)$. 
Table 4: Most frequently prescribed classes of medications.

\begin{tabular}{|c|c|c|c|}
\hline ATC code & ATC classification & $n(\%)$ & Medication \\
\hline B03/ A11 & $\begin{array}{l}\text { Antianaemic and } \\
\text { vitamins }\end{array}$ & $431(33.3)$ & $\begin{array}{l}\text { Iron, Folic acid, B complex, Multivitamin, } \\
\text { Vitamin C }\end{array}$ \\
\hline $\mathrm{R}$ & Respiratory drugs & $128(9.9)$ & $\begin{array}{l}\text { Chlorpheniramine, Loratadine, } \\
\text { Diphenhydramine, Bromhexine, } \\
\text { Budesonide + Formoterol, Salbutamol, } \\
\text { Salmeterol + Fluticasone, Montelukast } \\
\text { sodium, Salbutamol + Ipratropium } \\
\text { bromide, Terbutaline }\end{array}$ \\
\hline C & $\begin{array}{l}\text { Cardiovascular } \\
\text { drugs }\end{array}$ & $121(9.3)$ & $\begin{array}{l}\text { Labetalol, Propranolol, Nifedipine, } \\
\text { Methyldopa }\end{array}$ \\
\hline J01 & $\begin{array}{l}\text { Antibacterial for } \\
\text { systemic use }\end{array}$ & $103(8.0)$ & $\begin{array}{l}\text { Amoxicillin, Cefuroxime, Penicillin V, } \\
\text { Metronidazole, Erythromycin, Ampicillin }\end{array}$ \\
\hline A10 & Diabetic therapy & $86(6.6)$ & $\begin{array}{l}\text { Insulin aspart, Insulin glargine, } \\
\text { Insulin neutral HM, Insulin isophane HM, } \\
\text { Insulin detemir }\end{array}$ \\
\hline B01 & Antithrombotic & $65(5.0)$ & Acetylsalicylic acid \\
\hline N02 & Analgesic & $47(3.6)$ & Paracetamol \\
\hline A02 & $\begin{array}{l}\text { Acid related } \\
\text { disorders }\end{array}$ & $47(3.6)$ & $\begin{array}{l}\text { Ranitidine, Pantoprazole, Sodium } \\
\text { bicarbonate, Magnesium trisilicate } \\
\text { mixture }\end{array}$ \\
\hline G01 & $\begin{array}{l}\text { Gynecological } \\
\text { anti-infective and } \\
\text { antiseptics }\end{array}$ & $46(3.55)$ & Clotrimazole, Miconazole \\
\hline \multirow[t]{2}{*}{ H03 } & Thyroid therapy & $49(3.8)$ & $\begin{array}{l}\text { Levothyroxine sodium, Carbimazole, } \\
\text { Propylthiouracil }\end{array}$ \\
\hline & Miscellaneous & $172(13.3)$ & $\begin{array}{l}\text { Thymol gargle, Bromhexine, } \\
\text { Metoclopramide, Levetiracetam, } \\
\text { Lactulose, Furosemide, Corticosteroids }\end{array}$ \\
\hline
\end{tabular}

Table 5 shows that multivitamins (iron + folic acid + B complex) were the most prescribed drugs $(17.7 \%)$, followed by folic acid $(6.6 \%)$, vitamin C $(4.9 \%)$, and acetylsalicylic acid $(4.7 \%)$. 
Table 5: Most frequently prescribed drugs in pregnant women.

\begin{tabular}{lc|lc}
\hline Drugs & $\boldsymbol{n}(\%)$ & Drugs & $\boldsymbol{n}(\%)$ \\
\hline $\begin{array}{l}\text { Multivitamin } \\
\text { (iron + folic acid + B complex) }\end{array}$ & $229(17.67)$ & Labetalol & $34(2.62)$ \\
Folic acid & $85(6.56)$ & Bromhexine & $32(2.47)$ \\
Vitamin C & $64(4.94)$ & Chlorpheniramine maleate & $32(2.47)$ \\
Acetylsalicylic acid & $61(4.70)$ & Erythromycin & $31(2.40)$ \\
Thymol gargle & $56(4.32)$ & Insulin neutral & $30(2.31)$ \\
Ferrous fumarate & $55(4.24)$ & Ranitidine & $30(2.31)$ \\
Paracetamol & $52(4.01)$ & Metoclopramide & $28(2.16)$ \\
Cefuroxime & $51(3.9)$ & Carbimazole & $25(1.93)$ \\
Loratadine & $50(3.86)$ & Propylthiouracil & $21(1.62)$ \\
Propranolol & $49(3.78)$ & Levothyroxine & $18(1.39)$ \\
Methyldopa & $48(3.70)$ & Insulin detemir & $17(1.31)$ \\
Clotrimazole & $42(3.24)$ & Salbutamol & $16(1.23)$ \\
Diphenhydramine & $39(3.00)$ & Metronidazole & $14(1.08)$ \\
Insulin isophane & $36(2.78)$ & Salmetrol + Fluticasone & $11(0.85)$ \\
\hline${ }^{*}$ Miscellaneous drugs & & & $40(3.10)$ \\
\hline
\end{tabular}

Notes: *Magnesium trisilicate, Bisoprolol, Prednisolone, Duphastone, Amoxicillin, Heparin sodium (Enoxaparine), Budesonide + Formoterol (Symbicort), Montelukast sodium, Potassium chloride mist, Sodium bicarbonate, Calcium lactate, Calamine lotion, Penicillin V, Ampicillin, Insulin aspart, Frusemide and Levetiracetam.

It is apparent from Figure 2 that the most common medical conditions for the prescriptions were as supplements for essential minerals and vitamins, anaemia, allergic conditions, diabetes mellitus and hypertension.

\section{DISCUSSION}

Up to our knowledge, the present study is the first of its kind in Malaysia to investigate the rationality of drug prescriptions among pregnant women in a tertiary hospital.

In the current study, the same normality trend of WHO/INRUD values were obtained during all trimesters which is parallel with Indian study, (Midan and Komaram 2017) who reported similarities among all WHO/INRUD parameters during pregnancy trimesters.

The present study showed that $100 \%$ of prescribed drugs were by generic names which are in tune with previous Ethiopian and Indian studies where almost $100 \%$ of their prescribed drugs were by generic names (Gadisa and Guyo 2014; Midan and Komaram 2017). These findings are better than those found in Nigeria $(42.7 \%)$ and India $(21.5 \%)$ (Harsh et al. 2012) where only a few drugs were prescribed by generic names. The present results could be due to the presence of an electronic prescription system for outpatient clinics at HUSM that is designed to accept prescriptions by generic names only. 


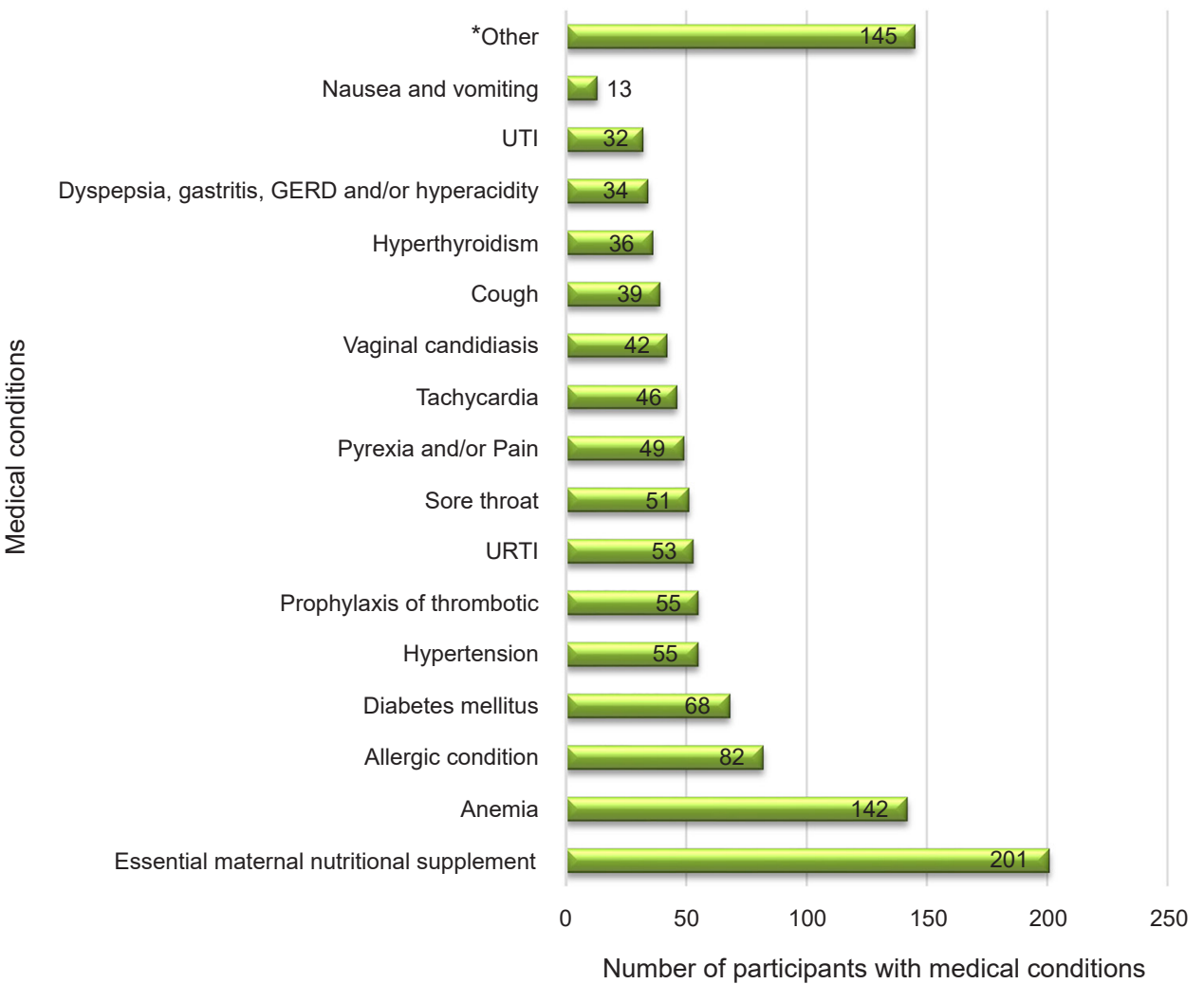

Figure 2: Common medical conditions among pregnant women in this study.

Notes: GERD = gastroesophageal reflux disease; URTI = upper respiratory tract infection; UTI = urinary tract infection; *Other = asthma, schizophrenia, threatened miscarriage, epilepsy, diarrhea, constipation, chronic rheumatoid heart disease, hypothyroidism, haemorrhoids, renal tubular acidosis, pruritus, eczema, thalasaessima, lymphadenitis, systemic lupus erythematosus, fungal infection, chronic bronchitis, soft tissue injury, itchiness and anxiety disorders.

In our study, the percentage of encounters with antibiotics and injections was low, while other indicators were normal. On the other hand, a previous study among general public in different states in Malaysia found different results in terms of the average number of prescribed drugs per encounter which was relatively high and the the percentage of encounters with antibiotics which were within normal range. Whereas, similar results were noticed with the percentage of encounters with injections which were low (Kamaruzaman and Ibrahim 2006) These differences could be justified by many issues as differences in study areas, target population and vulnerability of pregnant patients compared to public patients.

However, even if pregnant women are considered as vulnerabile patient, their prescriptions follow the references value of WHO/INRUD (Eze et al. 2007; UgwahOguejiofor 2014). 
Additionally, although the average number of prescribed drugs per encounter in the current study was within normal references value of WHO/INRUD, other results in Saudi Arabia and Brazil reported very high rates (Agarwal et al. 2014; Guerra et al. 2008). While the existing study reported a low percentage of pregnant women with antibiotics which is compatible with previous Ethiopian study (Gadisa and Guyo 2014), other studies in Nigeria and Ethiopia showed a very high rate of antibiotics prescriptions (Ugwah-Oguejiofor 2014; Desalegn 2013).

The present results showed a reduction in antibiotics during the first and second trimesters while the number of antibiotics prescribed during the third trimester was within the normal range listed by WHO/INRUD. This could be justified by physicians' worry about the harmful effects of antibiotics on the unborn baby, low percentage of pregnant women with medical indications that required antibiotics, or physicians' fear from the consequences of antibiotics resistance. Moreover, physicians normally hesitate to prescribe pregnant women with antibiotics during the early stage (first trimester) of pregnancy due to the risk on the fetus, while do not hesitate to prescribe pregnant women during the late stage of pregnancy. These findings justify the lower level of prescribed antibiotics in our study sample compared to those studies that were performed on the general public.

However, some medical conditions need treatment with antibiotics to avoid harmful consequences such as preterm delivery, low birth weight, UTI and vaginal candidiasis. Thereby there is a need to weight the benefits and risks of using antibiotics during pregnancy (Cram et al. 2002).

Although our results regarding the percentage of an encounter with injections were low (8.23\%), other studies in Ethiopia and India showed similar findings $5.8 \%$ and $2.17 \%$, respectively (Gadisa and Guyo 2014; Harsh et al. 2012), whereas other studies in Ethiopia were either very high (39.1\%) (Desalegn 2013) or within the normal range (Mesfin et al. 2015).

Nevertheless, using injections frequently may increase drug concentration in the body of pregnant woman and cause harmful or toxic effects on both mother and foetus. However, injection form is necessary in case of severe diseases that need quick onset of action with high drug concentrations. The balance between the benefit/risk of using injection drugs is highly important, particularly during pregnancy (Eze et al. 2007). However, the variation between studies could be justified by many reasons such as pregnant women characteristic, prescribers characteristic, the differences in disease patterns among pregnant women, and sometimes the cultural belief among people as they think that injection form is more powerful than other dosage forms and the prescribers might tend to prescribe injection according to their patients' expectations (Choi et al. 2012; Ofori-Asenso and Agyeman 2016).

Furthermore, an Indian study (Patel, Joshi and Patel 2013) reported lower rates of prescribed drugs from EDL $(80.79 \%)$ and hospital drug list $(32.5 \%)$ while the existing study showed that the prescribed drugs from both lists were $100 \%$. This result makes a good impression that all the needed medications were available to serve pregnant women properly in HUSM.

In the present study, a variety of drugs were prescribed to pregnant women. Most of them were relatively safe as a higher proportion of them $(34.0 \%)$ fall under category B of USFDA pregnancy category system. This is compatible with a recent Malaysian study (Jey et al. 2017) in 2017 that reported $50 \%$ of prescribed drugs belonged to category B but somewhat different from an Ethiopian and Saudi studies (Admasie, Wasie and Abeje 2014; Agarwal et al. 2014) as majority of prescribed drugs were from category A.

Furthermore, prescribed drugs from category $D$ were relatively low $(2.8 \%)$ and in accordance with Saudi study (1.33\%) (Agarwal et al. 2014) while considered much

Malay J Pharm Sci, Vol. 19, No. 1 (2021): 29-44 
lower than the findings by Admasie, Wasie and Abeje (2014) where prescribed drugs from category D represented $5.3 \%$.

Although results of the present study are coupled with those in Addis Ababa (Kasaye and Kahissay 2015) where most prescribed drugs during the second and third trimesters fell under USFDA category B with increasing the percentage of drugs that fell under category C, they are inconsistent with studies by Inamdar et al. (2012) and, Kureshee and Dhande (2013) where drugs under USFDA category A were dominant in all trimesters.

These variations between our study and others could be explained by variations in the health care systems, in the health needs of pregnant women and in the indicated maternal conditions in different countries. In addition, variations in the inclusion or exclusion of multivitamins and minerals could explain a lot of variations among different studies.

Moreover, the present study reported that paracetamol was widely used as an analgesic drug during pregnancy which is similar to the findings of a study in Nigeria (Eze et al. 2007). This could be due to the safety profile, cheap cost and good tolerability of paracetamol (Bremer et al. 2017; de Fays et al. 2015). However, a recent cohort study reported a correlation between chronic use of paracetamol and increase the risk of attention deficit hyperactivity disorder in infants (Brandlistuen et al. 2013).

Methyldopa and labetalol were found to be the most prescribed antihypertensive drugs. It is important to say that; methyldopa is considered the drug of choice for chronic hypertension treatment among pregnant women because of its long and short-term safety profile data regarding the growth and development of fetus who is exposed to the drug during pregnancy (Chobanian et al. 2003). However, labetalol does not has long-term safety data in children who are exposed to the drug during pregnancy (Kernaghan, Duncan and McKay 2012).

It is important to say that behavioural and socioeconomic variations among pregnant women as well as the health education and practice settings among healthcare professionals, could play a major role in the similarities and differences of our findings compared to other studies found in the literature (Choi et al. 2012).

On the other side, while many of previous studies were in tune with our study findings as the most commonly prescribed drug classes were anti-anaemic and multivitamins, the percentage of other prescribed drug classes were relatively different (Agarwal et al. 2014; Al-Hamimi and Al Balushi 2016; Kasaye and Kahissay 2015).

The first explanation might be the physiological changes that occur in pregnant women which demand different elements and vitamins. Also, pregnancy-related symptoms such as anaemia, UTIs, headache, gastritis, gestational diabetics and gestational hypertension are commonly happening during pregnancy.

Findings of this study are relatively in tune with another previous study in Malaysia that found $35 \%$ of pregnant women suffer from anaemia which makes anaemia a big challenging maternal health problem (Haniff et al. 2007). However, a higher level of anaemia was noticed in India (Patel and Gajjar 2015) and Palestine (Sawalha 2007) as the percentage of pregnant women with anaemia was $80 \%$ and $81.4 \%$, respectively.

Additionally, hypertensive disorders are considered the leading cause of mortality and morbidity among pregnant women especially the pre-eclampsia disorder (Singh 2009). The current study represented $(7.42 \%)$ of pregnant women with hypertension which is less than those in India where $10.97 \%$ of pregnant women had gestational hypertension (Midan and Komaram 2017). Also, diabetes during pregnancy is considered a public health problem in Malaysia particularly among Indian race followed by Malays and Chinese (National Obstetrics Registry, Clinical Research Centre and Ministry of Health Malaysia 2010). The present study findings were parallel with Indian study (Midan and Komaram 2017) as the rate of diabetes among pregnant women was $8.54 \%$. 
The frequent types of infections among pregnant women in the current study were upper respiratory tract infections (URTIs), UTIs and vaginal candidiasis. URTIs are considered as one of the most common infections during pregnancy and often caused by viruses (Collier et al. 2009).

However, while the rate of pregnant women with URTIs in Ethiopian (8.79\%) (Gadisa and Guyo 2014) and Indian (7.8\%) (Kureshee and Dhande 2013) studies were in tune with our results (7.15\%), other Ethiopian and Indian studies reported either higher $(12.8 \%)$ or lower $(2.2 \%)$ percentage of URTIs (Mary, Chandrakala and Tekulapally 2015; Mesfin et al. 2015), respectively.

Generaly, many reasons might clarify the variations in the prevelance of medical conditions among pregnant women in different studies such as level of wealth, level of education, level of food insecurity and occupation (Lebso, Anato and Loha 2017).

\section{Study Limitations}

This study faced some limitations that need to be considered when interpreting the results. Nevertheless, it is unlikely that those limitations affected on the study results.

(i) The study was conducted in a single tertiary hospital. Since the sample size does not represent all Malaysian states, the results cannot be generalised.

(ii) Some of the prescribed drugs are unclassified according to the USFDA pregnancy categories. This presents a limitation of the study ability to perform a comprehensive evaluation of the prevalence of potentially harmful drugs on the unborn baby. Thereby, the study evaluation could be considered conservative.

(iii) Since the last prescription only was selected from each medical file, thereby previous drugs or any prescription after the review date was not included.

\section{CONCLUSION AND RECOMMENDATIONS}

The present study reported that majority of WHO/INRUD indicators were in the normal range while others were out of range which means that there is still a room for improvements and more attention from health staff is required regarding those indicators. Although the rate of prescribed drugs from categories $D$ and $X$ were relatively low, still these drugs should be avoided as much as possible during pregnancy. Medications should be evaluated carefully, weighing the benefits versus the risks for unborn baby and mother particularly with antiepileptic drugs, especially when the suitable alternative is not available.

However, the study findings presented great caution and careful prescribing behaviour of physicians in gynaecology/obstetric departments and most of the prescribed medications were rational and safe during pregnancy.

However, The researchers belief, there is still a need to encourage medical staff for continuous education and to read update scientific publications continuously which will be definitely improve their knowledge and positively reflected in their practice.

Future study is recommended to replicate this research at the national level by including several states to ensure the generalisability of the results for the whole country.

Malay J Pharm Sci, Vol. 19, No. 1 (2021): 29-44 


\section{REFERENCES}

ADMASIE, C., WASIE, B. \& ABEJE, G. (2014) Determinants of prescribed drug use among pregnant women in Bahir Dar city administration, Northwest Ethiopia: A cross sectional study, BMC Pregnancy and Childbirth, 14(1): 325. https://doi.org/10.1186/1471-2393-14 $-325$

AGARWAL, M., NAYEEM, M., SAFHI, M., MAKEEN, H., SUMAILY \& NAKUL, G. (2014) Prescribing pattern of drugs in the department of obstetrics and gynecology in expected mothers in Jazan Region, KSA, International Journal of Pharmacy and Pharmaceutical Sciences, 6(1): 658-661.

AL-HAMIMI, J. \& AL BALUSHI, K. (2016) Patterns of prescription drugs use among pregnant women at Sultan Qaboos University Hospital and Sultan Qaboos University Hospital Family and Community Medicine Clinic, Oman, Journal of Pharmacy \& Bioallied Sciences, 8(4): 309-313. https://doi.org/10.4103/0975-7406.199347

ANDRADE, S., GURWITZ, J., DAVIS, R., CHAN, K., FINKELSTEIN, J., FORTMAN, K. et al. (2004) Prescription drug use in pregnancy, American Journal of Obstetrics and Gynecology, 191(2): 398-407. https://doi.org/10.1016/j.ajog.2004.04.025

BATAINEH, Z., KHASAWNEH, N., KOFAHI, S. \& AL-MOQASQAS, M. (2013) Assessment of drug use by diabetics-experience at JUST Primary Health Care Center in Irbid, Jordan, Jordan Journal of Applied Science, 11(1): 45-55.

BHARTIY, S., SHINDE, M., NANDESHWAR, S. \& TIWARI, S. (2008) Pattern of prescribing practices in the Madhya Pradesh, India, Kathmandu University Medical Journal, 6(1): 5559.

BRANDLISTUEN, R., YSTROM, E., NULMAN, I., KOREN, G. \& NORDENG, H. (2013) Prenatal paracetamol exposure and child neurodevelopment: A sibling-controlled cohort study, International Journal of Epidemiology, 42(6): 1702-1713. https://doi.org/10.1093/ije/ dyt183

BREMER, L., GOLETZKE, J., WIESSNER, C., PAGENKEMPER, M., GEHBAUER, C., BECHER, $H$. et al. (2017) Paracetamol medication during pregnancy: Insights on intake frequencies, dosages and effects on hematopoietic stem cell populations in cord blood from a longitudinal prospective pregnancy cohort, EBioMedicine, 26: 146-151. https://doi.org/10.1016/j.ebiom.2017.10.023

CHOBANIAN, A., BAKRIS, G., BLACK, H., CUSHMAN, W., GREEN, L., IZZO, J. et al. (2003) The seventh report of the Joint National Committee on Prevention, Detection, Evaluation, and Treatment of High Blood Pressure, Journal of American Medical Association, 289(19): 2560-2572. https://doi.org/10.1001/jama.289.19.2560

CHOI, K., PARK, S., LEE, J. \& KWON, S. (2012) Factors affecting the prescribing patterns of antibiotics and injections, Journal of Korean Medical Science, 27(2): 120-127. https://doi.org/10.3346/jkms.2012.27.2.120 
COLLIER, S., RASMUSSEN, S., FELDKAMP, M. \& HONEIN, M. (2009) Prevalence of selfreported infection during pregnancy among control mothers in the National Birth Defects Prevention Study, Birth Defects Research Part A, Clinical and Molecular Teratology, 85(3): 193-201. https://doi.org/10.1002/bdra.20540

CRAM, L., ZAPATA, M., TOY, E. \& BAKER, B. (2002) Genitourinary infections and their association with preterm labor, American Family Physician, 65(2): 241-248.

DE FAYS, L., VAN MALDEREN, K., DE SMET, K., SAWCHIK, J., VERLINDEN, V., HAMDANI, J. et al. (2015) Use of paracetamol during pregnancy and child neurological development, Developmental Medicine \& Child Neurology, 57(8): 718-724. https://doi .org/10.1111/dmcn. 12745

DESALEGN, A. (2013) Assessment of drug use pattern using WHO prescribing indicators at Hawassa University Teaching and Referral Hospital, South Ethiopia: A cross-sectional study, BioMed Central (Health Services Research), 13(1): 170. https://doi.org/10.1186/1472 $-6963-13-170$

EZE, U., EFERAKEYA, A., OPARAH, A. \& ENATO, E. (2007) Assessment of prescription profile of pregnant women visiting antenatal clinics, Pharmacy Practice, 5(3): 135-139. https://doi.org/10.4321/S1886-36552007000300007

GADISA, D. \& GUYO, W. (2014) Drug prescribing pattern and its potential fetal harm among pregnant women in Bishoftu General Hospital, Oromia Regional State, Ethiopia, European Journal of Pharmaceutical and Medical Research, 1(1): 13-34.

GUERRA, G., DA SILVA, A., FRANCA, L., ASSUNCAO, P., CABRAL, R. \& FERREIRA, A. (2008) Drug use during pregnancy in Natal, Brazil, Revista brasileira de Ginecologia e Obstetricia, 30(1): 12-18.

HANIFF, J., DAS, A., ONN, L., SUN, C., NORDIN, N., RAMPAL, S. et al. (2007) Anemia in pregnancy in Malaysia: A cross-sectional survey, Asia Pacific Journal of Clinical Nutrition, 16(3): 527-536.

HARAMBURU, F., MIREMONT-SALAME, G. \& MOORE, N. (2000) Good and bad drug prescription in pregnancy, Lancet, 356(9243): 1704. https://doi.org/10.1016/s0140 $-6736(00) 03202-5$

HARSH, J., SEJAL, P., KAMLESH, P. \& PATEL, V. (2012) Drug use pattern during pregnancy: a prospective study at tertiary care teaching hospital, NHL Journal of Medical Sciences, 1(1): 14-16.

HOGERZEIL, H. V., BIMO, ROSS-DEGNAN, D., LAING, R., OFORI-ADJEI, D., SANTOSO, B. et al. (1993) Field tests for rational drug use in twelve developing countries, Lancet, 342(8884): 1408-1410.

INAMDAR, I., ASWAR, N., SONKAR, V. \& DOIBALE, M. (2012) Drug utilization pattern during pregnancy, Indian Medical Gazette, 145(8): 305-311. 
JEY, V., SIEW, S., RITA, M. \& OMAR, S. (2017) Medications used by pregnant women: Any safety concerns? International Journal of Pharmacy and Pharmaceutical Sciences, 9(5): 100-106. https://doi.org//10.22159/ijpps.2017v9i5.16057

KAMARUZAMAN, S. \& IBRAHIM, M. (2006) How rational are drugs used in Malaysian primary health care sector?, Malaysian Journal of Pharmaceutical Sciences, 4(1): 1-12.

KASAYE, E. \& KAHISSAY. (2015) Assessment of drug prescribing pattern among pregnant women attending antenatal care in health centers found in Arada subcity, Addis Ababa, Ethiopia, Journal of Pharmaceutical Science and Bioscentific Research, 5(4): 347-362.

KERNAGHAN, D., DUNCAN, A. \& MCKAY. (2012) Hypertension in pregnancy: A review of therapeutic options, Obstetric Medicine, 5(2): 44-49. https://doi.org/10.1258/om .2011 .110061

KURESHEE, N. \& DHANDE, P. (2013) Awareness of mothers and doctors about drug utilization pattern for illnesses encountered during pregnancy, Journal of Clinical and Diagnostic Research, 7(11): 2470-2474. https://doi.org/10.7860/JCDR/2013/6329.3582

LEBSO, M., ANATO, A. \& LOHA, E. (2017) Prevalence of anemia and associated factors among pregnant women in Southern Ethiopia: A community based cross-sectional study, PLoS One, 12(12): e0188783-e0188783. https://doi.org/10.1371/journal.pone.0188783

MAROTE, C. (2014) Assessment of risk perception of teratogenicity of commonly used drugs among pregnant women. Master diss. University of Zimbabwe, Zlmbabwe. Retrieved from: http://ir.uz.ac.zw/xmlui/bitstream/handle/10646/2667/Marote_Assessment_of_risk _perception_of_teratogenicity_of_commonly_used_drugs_.pdf?sequence=4\&isAllowed=y

MARY, J., PURNA, C. \& TEKULAPALLY, K. (2015) Drug utilization pattern in pregnant women in a tertiary care hospital, Hyderabad, Telangana, Journal of Chemical and Pharmaceutical Research, 7(7): 184-188.

MESFIN, F., DEREJE, K., WOTE, A. \& GASHE, F. (2015) Drug utilization pattern and potential teratogenicity risk among pregnant women visiting antenatal clinic: The case of a primary hospital, Indian Journal of Pharmacy Practice, 8(1): 27-33. https://doi.org/10.5530/ ijopp.8.1.6

MIDAN, D. \& KOMARAM, R. (2017) Assessment of drug utilization pattern and teratogenicity risk among pregnant women attending a tertiary care hospital, Andhra Pradesh, International Journal of Pharmaceutical Sciences and Research, 8(12): 52915297. https://doi.org/10.13040/IJPSR.0975-8232.8(12).5291-97

MIMS PTE. (2017) Search drug information. https://www.mims.com/malaysia

NATIONAL OBSTETRICS REGISTRY, CLINICAL RESEARCH CENTRE, \& MINISTRY OF HEALTH MALAYSIA (2010) The second report of National Obstetrics Registry (NOR). (Second edition). http://www.crc.gov.my/publication/report

OFORI-ASENSO, R. \& AGYEMAN, A. (2016) Irrational use of medicines-a summary of key concepts, Pharmacy, 4: 1-13. https://doi.org/10.3390/pharmacy4040035 
PATEL, K., JOSHI, H. \& PATEL, J. (2013) A study of morbidity and drug utilization pattern in indoor patients of high risk pregnancy at tertiary care hospital, International Journal of Reproduction, Contraception, Obstetrics and Gynecology, 2(3): 372-378. http://www.ijrcog.org/index.php/ijrcog/article/view/111

PATEL, P. \& GAJJAR, B. (2015), Comparison of prescribing by private and institutional obstetricians in pregnant women, International Journal of Medical Science \& Dental Health, 1(1): 7-15.

SALWE, K., KALYANSUNDARAM, D. \& BAHURUPI, Y. (2016) A study on polypharmacy and potential drug-drug interactions among elderly patients admitted in department of medicine of a tertiary care hospital in Puducherry, Journal of Clinical and Diagnostic Research, 10(2): FC06-FC10. https://doi.org/10.7860/JCDR/2016/16284.7273

SAWALHA, A. (2007) Consumption of prescription and non-prescription medications by pregnant women: A cross sectional study in Palestine, The Islamic University Journal, 15(2): 41-57. http://repository.yu.edu.jo/handle/123456789/445281

SINGH, H. (2009) Pre-eclampsia: Is it all in the placenta? The Malaysian Journal of Medical Sciences, 16(1): 7-15. http://www.ncbi.nlm.nih.gov/pmc/articles/PMC3336172/

TRUVEN HEALTH ANALYTICS. (2012) IBM Micromedex. https://www.micromedex solutions.com/home/dispatch

UGWAH-OGUEJIOFOR, C. (2014) Drug utilization pattern in pregnancy in a tertiary hospital in Sokoto, North West Nigeria, Journal of Health Sciences, 4: 99-104.

WHO. (1993) How to investigate drug use in health facilities: Selected drug use indicators (WHO/DAP/93.1). (Geneva: WHO). http://apps.who.int/medicinedocs/en/d/Js2289e/

WHO. (2011) The world medicines situation rational use of medicines. (WHO/EMP/ MIE/2011.2.2). (Geneva: WHO). http://apps.who.int/medicinedocs/en/m/abstract/Js18064en/

WHO. (2012) The pursuit of responsible use of medicines: sharing and learning from country experiences (WHO/EMP/MAR/2012.3). (Geneva: WHO). https://www.who.int/medicines/ publications/responsible_use/en/

WHO. (2018) The anatomical therapeutic chemical classification system with defined daily doses (ATC/DDD). https://www.whocc.no/atc_ddd_index/ 